\title{
TECHNOLOGY EFFECT ON THE LEADER BEHAVIORS IN THE DIGITAL ERA
}

\author{
Hakan Kapucu $^{1}$ \\ ${ }^{1}$ Hafizata Sokak, Mecidiyekoy, Sisli, 34387, Istanbul, Turkey, hakan.kapucu@techie.com, \\ hakan.kapucu@consultant.com
}

\begin{abstract}
Human behaviors are affected by rapidly-changing conditions, and so do leaders. Leaders play essential roles in shaping the planet, world, and businesses. Like all the other organisms, they communicate with the outside world. On one side, leaders affect the outside world, and on the other, leaders are also affected by it. Technological advancements affect leader behaviors, decisions, insights, lifestyles, and it even impacts leaders' selves. Although digital transformation has become so central, and it has challenges for leaders and organizations, the studies are deficient in the quantity that links and associates leader and digital transformation. In this context, this research deals with answering two clear and vital questions: Which characteristics create effective and efficient business leaders, and how leader behaviors are affected by digital transformation. This research finds skills and key behaviors the leader of today and the future possesses, which potential leaders can adopt and employ. On the other side, it reveals the challenges this disruption causes and its effect on leaders. It moreover brings a holistic approach to provide a paradigm for leadership. These would guide us to understand how digital transformation disrupts the leadership process and where it will evolve next. Other measures of progress are to emphasize the leaders' interplay with technology, the leadership spectrum, and what is required for leaders to adopt and adapt to the changing world from technological and universal perspectives.
\end{abstract}

\section{Keywords}

Technoversal Leader; Self-Created-Problem-Solution Cycle; APARTS Behaviors; Technology Leader Interaction; Technology Management.

\section{JEL Classification}

M12, M15, M54

DOI: $\underline{\text { https://doi.org/10.14311/bit.2020.03.02 }}$

Editorial information: journal Business \& IT, ISSN 2570-7434, CreativeCommons license (c) (i) published by CTU in Prague, 2020, http://bit.fsv.cvut.cz/ 


\section{Introduction}

In addition to the leader and follower interaction, which naturally boils down to the essence of leadership along with task completion, technology began disrupting leader behaviors - as it disrupts the way that we live, environment shapes, and businesses run.

Considering the roles of leaders in shaping the environment and businesses, the interplay of leader and digital transformation necessitates a more comprehensive understanding both in academia and business-related research institutions. Yet, a gap at various dimensions of this significant subject exists (Bolden \& O’Regan, 2016, pp. 438-439; Khan, 2016; Avolio et al., 2014, pp. 105-126).

To understand how the leaders changed and where leadership evolves in the future, it has seemed necessary to analyze it from the initial point that it goes through. Comprehension of what leadership concept currently is and will possibly be in the future needed to understand: What leadership was, and which behaviors created and are creating effective and efficient leaders. So the first primary question showed up as to which characteristics foster ideal business leaders. And once the effective leadership and its constituents have comprehended, then, it was possible to ask the second question: How leader behaviors are affected by digital transformation. Exactly where it has reached in the digital era, and where will it possibly morph. Some measures of progress are as follows: Emphasizing leaders' interplay with technology, understanding leadership continuum, what challenges leaders do come up against when they lead in the digital era, and which key factors leaders need to adopt and adapt from technological and universal perspectives for overcoming these challenges and getting ahead.

A holistic, systematic, and algorithmic approach has planned and adopted for accomplishing the objectives and goals. While executing this approach, different means employed: Participation in the Management and Leadership Summit (Deegan et al., 2020), completion of a course (University of Virginia \& Boston Consulting Group, 2018), webinars and robot exhibition, combining and comparing the pieces of research executed by respected institutions which study behavioral aspect of ideal leaders, literature review (the references narrowed down to the last eight years considering the context of the research subject), and interviews have followed all these pieces of work and analyses.

Achieving the goals of this research is significant both for the people who want to possess leader behaviors and for the researchers who study leadership and its interaction with technology.

\section{Literature Review}

In this section, the researcher delves into the literature for finding relevant knowledge of the individuals with the highest potential to lead in today and future, the behaviors that are changing potential leaders into effective ones, how technology is transforming the perception of leadership, and leaders' interaction with the digital era. This research brings a holistic approach related to the ideal leader's qualities. Rather than researching a leader's adopted style, it aims to study all the core qualities driving a potential leader to success. And to become the leader of today and the future, the review aspires to reveal all remarkable qualities possessed by various types of leaders.

\subsection{The Transition From Conventional to New Era Leadership}

A digital leader harmonizes challenges with the alignment of new technologies with existing IT and support from technological partners (Della Corte et al., 2019). Digital leadership is not only managing businesses in the age of artificial intelligence but also requires possessing the right skillset to stimulate technological advancement and innovation. The digital leader creates engaged and skilled 
teams (Bawany, 2019, p. 28; Della Corte et al., 2019). The mindset of an entire organization signifies more than IT infrastructure. The expansion of new digital technologies with the rise of new disruptive threats is permeating to the core of businesses. Hence digitalization becomes a significant assignment for companies to accomplish (Rogers, 2016). Despite digitalization's effects on organizations and leaders, a gap has happened amid the research of contemporary leadership and digital transformation (Khan, 2016). In the era of digitization and technology, there is a need for more pieces of research that will reveal the effect of digital transformation on leaders.

\subsection{Requirements for Leaders to Adapt and Adopt to the Changing Technological World}

Technology as a solution mechanism to problems may trigger simultaneous informational and environmental matters because human errors and feeling are coming into play as a variable. Cortellazzo et al. (2019) report that new ethical concerns that arise from digital transformation are an issue for leaders. For instance, excessive use of digitalization processes inflicting information overload on employees and making the lines indistinct that separate personal and work life, which they called the dark side of digital transformation.

According to a piece of research, which conducted by The Economist Intelligence Unit, it demonstrated that motivating ability, innovation, stress management, being empathetic, and transparency would be significant in the next three years (2017). Although these skills matter and around three years passed, the later research and another piece of almost simultaneous work, to some extent, brought different skillset into consideration about the digital era than The Economist Intelligence Unit did (Korn Ferry, 2019; Neubauer et al. 2017). A primary challenge for organizations is not only implementing the right technology, but it is also culture and skills in the organization; the perspective and attitudes of an entire organization signify more than IT infrastructure (Oberer \& Erkollar, 2018; Rogers, 2016). Leaders have not only been affected by this culture, and according to Cortellazzo et al. (2019), they play a role in the development of digital culture.

Founded by Nikolai D. Kondratiev, resulting from technological advancement, the Kondratiev wave is not a generally accepted theory by economists, and the interpretation for it can be a statistical illusion (Chappelow, 2020). Yet, there is an opposite point of view, which was reported by Rios et al. that the capitalist expansion built on information and communication technologies could be a rising Kondratiev wave from the beginning of the 1980s until the financial crisis in 2008 (2018, p. 270). Whether the research proves or opposes the plausibility of these long-lasting waves, a couple of things become clear related to the cycles: Technology and digital transformation will continue to represent a large field in economics, and it will progress by bringing many novelties along with challenges. And it will increasingly keep leaders' agenda busy for a very long time, and maybe irrevocably.

The creation of engaged and skilled teams appears as a requirement for leaders in the digital age (Bawany, 2019, p. 28; Della Corte et al., 2019). Organizations and leaders must realize that the most crucial challenge of digital transformation comes from necessary talent absence (Sainger, 2018, pp. 2-5). Although digital transformation may be increasing the need for talented teams, team creation and teamwork are essential almost for all organizations that the majority of leadership styles require.

Avolio et al. (2014) argue that the impact and importance of advanced information technology (AIT) perceived by scholars. Yet the interplay of this technology on how people work together and on leadership keep remaining at the very nascent levels-later studies showed that this gap, for different leadership styles, related to the technology and leader interaction still exists (Khan, 2016). Avolio et al. point out ethical considerations that happen because AIT will be critical for leaders, and they emphasize the significance of gamification (2014, pp. 105-126). The role and four leadership foci of digital business transformation defined as leading cultural change, strategy, leading network, and enabling. Instead of hierarchical leadership, which is unsuitable for the new business environment, the leader provides support and enables employees to reach their goals. In doing this, the leader promotes 
dialogue and recognize that employees are expert at what they do, and this challenges the traditional leader's role (Larjovuori et al., 2018, pp. 1-7). They must develop and improve their operations and services through new collaborations and partnerships (Larjovuori et al., 2018, pp. 1-7; University of Virginia \& Boston Consulting Group, 2018). The old methods of leading people are no more functional in the creative economy (Larjovuori et al., 2018, pp. 1-7; Jakubik \& Berazhny, 2017, pp. 471-483), at which competitive advantage bases on learning and innovation. Collaborative learning, co-creation, building networks, and connecting people have strong influence rather than a command and control mechanism (Jakubik \& Berazhny, 2017, pp. 471-483). And according to Jakubik and Berazhny (2017), a new leadership model is emerging: An Altrocentric leader who distributes the authority. Few characteristics of this leadership can relate to servant leadership, such as empathy or primary concern for the others. Or delegating power can also interrelate as another common aspect of these two leaderships. Both of these styles have intellectual, humanistic thus outstanding qualities, although the fact that servant leadership originates from earlier periods. Yet, in societies in which domination is stronger than sharing power with others, modesty and meekness are perceived as its weaknesses (Gandolfi et al., 2017, pp. 351-356). It becomes apparent that leaders require other additional qualities, especially in the digital era.

Although technology knowledge alone does not appear to be enough for leaders to control, leaders still require to adopt and obtain it. Because leaders will have to deal with data-driven-decision making, which is a challenge for leaders (Hesse, 2018); thus, the new role of a leader is a data and information mentor (Jakubik \& Berazhny, 2017, pp. 471-483). Jakubik and Berazhny also add challenges that digitalization brings on leadership: communication skills include face-to-face connection and human touch. Even though the behavior-agility-has not been accentuated, they still mentioned that there is a demand for a new type, an agile leader (2017, pp. 471-483), which they actually could emphasize as another significant finding.

Industry 4.0 and digital transformation processes are more efficient and effective with particular attitudes, knowledge, and skillset (Korn Ferry, 2019; Neubauer et al., 2017; Prince, 2017; The Economist Intelligence Unit, 2017). And Prince adds that the digital leadership framework grounds on a matrix that links transactional, transformational, and authentic leadership (2017, pp. 132-139). Transpersonal leadership is to learn to balance rational, emotional, and spiritual qualities for excellent leadership (Grant, 2020, pp. 43-44). The search for ideal leaders tends to combine different leadership styles or skill sets. Since leadership styles are too many to determine a great leader from them for leading in the technology era, another solution is needed. This time, it is not combining different leadership styles but finding distinctive, overlapping skill sets and behaviors defining effective and efficient leaders, which used while creating these leadership styles. It will be in the light of recent pieces of research, which conducted by respected organizations that cover 365,191 employees and leaders from all levels. Additionally, there will be an analysis of 13 top-level executives for two days ( 15 hours). And other than that, interviews have been executed with another group of leaders.

\subsection{Ideal Leader of Technology Era}

Digitalization offers new possibilities like virtual teams, introduces new means of communication, increases speed and access to information, impacts power structures, thus, causes efficiency, standardization, and smart working. The primary skills that leaders need for benefiting from this transformation: the use of digital assets as communication tools, decision making at high speed, building networks, leading in a disruptive environment, and the shift from emotional and social intelligence to technical skills (Cortellazzo et al., 2019, pp. 1-13). Behavior can be the key. By analyzing behavior, the nature of leadership could be fathomed better (Robbins \& Coulter, 2016, pp. 524-535). However, the percentage of leaders who carry the necessary properties is considerably-low, so businesses immediately need to develop new leaders. On a global scale, as regards Korn Ferry, the 
majority of investors think the current leadership will not answer the needs of the future (2019). So by which behaviors' exhibition leader can get ahead! Not hierarchical, but collective leadership is more convenient today. Being an omnipotent ruler is no longer useful-trying to have unlimited authority over people - and trying to be an omniscient leader, who is aware of all, is also obsolete. Leaders must be ready to collaborate with others who are better than them (Rodríguez et al., 2019, pp. 22-24). The tendency to depend on the past only or to avoid using the obtained experience in the past will not bring about success (Grigsby, 2015, pp. 125-128). The complexity of leadership roles requires an effective leader to acquire new behaviors and to enact them.

\section{Data and Method}

Producing this research and creating value are results of multistage work. Each stage has a distinctive approach, and the linkage of these approaches brings about complete and well-established work.

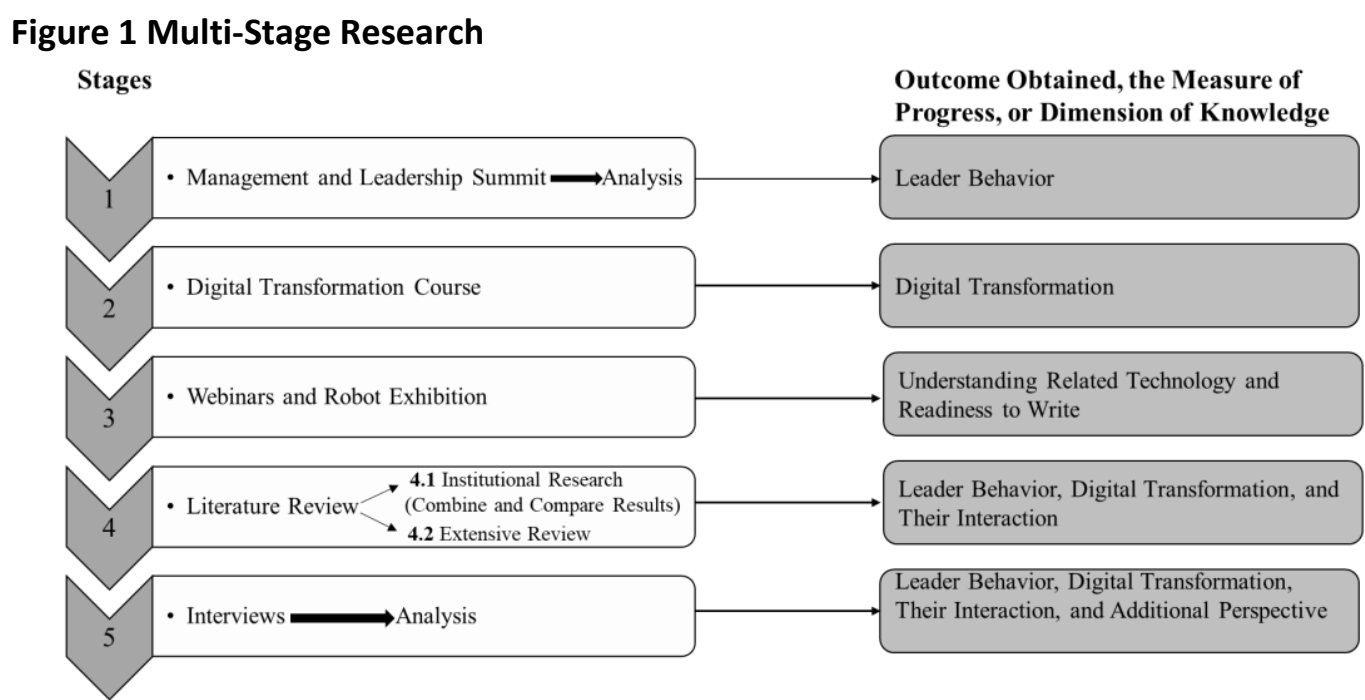

Note. The diagram illustrates the stages of this research and the outcomes obtained from relevant parts. The author has produced and prepared it, 2020.

In March 2020, the Management and Leadership Summit has taken place in Istanbul, 13 toplevel executives have attended the organization (Deegan et al., 2020). The leadership summit has been before beginning the literature review. So, An Analysis of Leaders for Finding Their Common Behaviors (Appendix A) has conducted earlier. The objective has been to unveil the behaviors that bring success to the highest-level business leaders of Turkey in their fields. A later review of literature has demonstrated significant common findings in parallel with this analysis (de Smet et al., 2019, pp. 2834; Korn Ferry, 2019; Neubauer et al., 2017). These leaders work in different industries: holdings, sport, pension company, human resources, banking, fast-moving consumer goods companies, tobacco companies, pharmaceutical companies, and telecommunications. The total observation time has been 15 hours, and the observation group has got 13 leaders. Data obtained from this stage, via content analysis, has been analyzed. This analysis is a blended approach: as the qualitative step, category assignment to the text. And as the quantitative step, working through it and analyzing category frequencies (Mayring, 2014, pp. 10-15).

Although digital transformation is part of people's lives, it has still required to have a deeper understanding to be able to notice critical points that hide in technology, which relate to humans and play a role in human and machine interaction. In this framework, the researcher has completed a course to have a general understanding of digital transformation. Basics, economics, trends, and 
strategy of digital transformation have been analyzed further (University of Virginia \& Boston Consulting Group, 2018).

"Digitalization's Effect on Work and Human Relations," the webinar has been followed. The information provided at this webinar, in earlier studies, has already been covered, so it has been convenient to see that the sufficient amount of knowledge gained for writing about digital transformation. "Next-Generation Robots Exhibition" has been visited. The purpose of ensuring this participation has been to understand the integration of digital transformation in robots and having another understanding of technology.

The literature review comprises of various components. Peer-reviewed articles, large pieces of research conducted by respected institutions, books, journals, proceedings, conferences, courses, business magazines, reports, webinars, summits, complementary information on matters by various sources, and field studies: These parts together construct the body of the literature review. The research has categories: leadership, digital transformation, and effect (interaction). A detailed search has been carried on each of these parts followingly. An overall holistic approach, along with the algorithmic and systematic analysis, has been adopted. When searching for relevant literature, approximately 6,000 data have raked for elimination. Yet, the use of sources has consequently remained at around one percent (references/data). From these data, a more narrowed review has gotten through the use of specific keywords. It has enabled pinpointing the connections that link each of the research parts, which helped to bring the complete research into a form, which is a whole standalone piece of work. The dates of references have narrowed down to the last eight years with the expectation of presenting the most state-of-the-art research by considering the subject of it. Comparison and combination of the latest pieces of research related to the behavioral aspect of the leaders have achieved to find which leader behaviors matter most for a large number of leaders and employees $(N=365,191)$. Numeral represents the population in this research that examines the behavioral aspect of ideal leaders, and it only includes institutions. While determining the great leader's characteristics, popularity (to be mentioned in documents) has not been selection criteria, but these behaviors' importance, and being chosen by employees and leaders has been. In essence, what makes a leader successful in the eye of them. As a finding, the behavior must be in one or more than one large observation group, or additionally, it can also be supported by individual researchers or academicians in addition to the institutions.

And interviews have followed all these pieces of work and analyses. So, they have come after the leadership summit, which covered top-level leaders and companies from different industries. And since interviews have been the final stage, they have also taken place after analyzing respected institutions' studies, which globally has covered employees and leaders from all levels and different sectors. Given this information, interviews have expanded to another industry. The industry is not studied earlier in the digitalization framework (in this research). For covering an area as large as possible, this research has targeted to bring diversity. With the hope of gaining additional perspective, the interviews have extended to the intermediate goods industry among the small and medium-sized enterprises (less than 250 employees). Nine companies and 13 leaders have participated in interviews. Each interview took 39 minutes on average (Appendix B). Interviews are structured. All relevant correspondences and interviews, in written format, have been recorded. They conducted on digital platforms considering the current global situation (outbreak of pandemic) for not risking health. The researcher has applied qualitative content analysis (QCA) to the data that have come from the interviews. Content analysis (CA) is a general phrase to define the process of reducing textual data into quantifiable segments after coding. CA includes outlining the research problem, obtain the source of material, identify the focus of research, and count the occurrence of categories (Marvasti, 2019). QCA, on the other hand, is a procedure that systematically describes the meaning of qualitative material, which is done by the classification of material as instances of categories of coding (Schreier, 2012, p.1). 
According to Marvasti, QCA analytically positions between the qualitative and the quantitative views of qualitative research (2019). To complete statistical coding on the material from the interviews, programs and computer-aided analysis have been used.

\section{Interiorizing Leadership and Digital Transformation}

Leadership, digital transformation, leaders, history of leadership from past to today, challenges of the digital era are needed to assess for a better understanding of outcomes - very briefly, the theory. On the other hand, a new leader type finds a place in this part (chapter 4.4).

\subsection{A workaholic, a Dictator, or an Influencer: The Ways Leaders Differ or Exhibit Common Behaviors}

Every organism on the earth is accepted as part of natural phenomena: plants, animals, people. They interact or impact one another. In this circle, many take the role of a worker or a soldier. And only a few of them take the role of a leader. The business world and academia define and explain many leadership styles. In recent years, it has kept adding new ones to the existing literature: A few of them are bold leaders, self-disruptive leaders, digital leaders, and virtual leaders. On the other side, this research also focuses on the leaders that acted as a part of changing history: transformational leaders, transactional leaders, and autocratic leaders. In other words, influencers the ones who transform, workaholics the ones who transact, and autocrats the ones who dictate! Transformational leaders urge and invigorate followers to accomplish outstanding results. Transactional leaders introduce objectives and provide rewards in return. Autocratic leader, on the other hand, mandates unilateral decisions, and limited personnel engagement (Robbins \& Coulter, 2016, pp. 525, 532).

\subsection{Comprehending Yesterday and Today of the People With Authority}

The process of leading people alters in any era, so it does require adapting the necessary skills. This concept was different in the past than it is today. Researching yesterday will advise us to realize today and anticipate the future of the leadership process.

Leadership theories divided into categories as early leadership (theories of trait and behavior), theories of contingency (model of Fiedler, the situational theory of Hersey and Blanchard, and model of path-goal), and contemporary views (exchange of leader-member, transactional-transformational view, and visionary-charismatic view (Robbins \& Coulter, 2016, pp. 524-535). Technology, more than ever, is becoming a key element in shaping leader behaviors. With the revolutionary technological advancement, leaders are developing too. They find themselves in an environment, which forces them to challenge, adapt, and making them embrace new phenomena, new models, and styles. Virtual, digital, disruptive leadership styles and leadership 4.0 concepts have risen in the last few decades or even more recently. There are many different opinions when it is coming to the type of leadership fitting into the digital era and future. Just a few of these ideal leader figures: Transformational leadership is an exemplary model that gives the potential to avail all stakeholders of the organizations (Giroux \& Mclarney, 2014, p. 863); or more recent ones, such as self-disruptive leaders of Korn Ferry (2019); transpersonal leader (Grant, 2020, pp. 43-44); agile leaders (Neubauer et al., 2017) found better compared to other ones in answering effective leadership and organizations' needs. On the other side, variables for foreseeing a person's potential to become a leader: insight, engagement, determination, and curiosity. Such behavioral necessities are creating terms such as Chief Behavioral Officer (СВO). Performance is an outcome of behavior, so Chief Executive Officer, on the other hand, should adapt to become a Chief Behavioral Officer (Rodríguez et al., 2019, pp. 22-24). Instructing new leadership behaviors necessitates a "behavioral protocol," which consists of heuristic rules for following under a specific situation. After defining the frame of contingency that the leader surrounded, these rules will shape the behaviors. Gaining these rules makes the leader pass beyond knowing but verily doing (Grigsby, 2015, pp. 125-128). 


\subsection{From the Beginning of the Industrial Revolution to the Digital Era and the Global Challenges of Digital Transformation}

The human mind is more adapted to linear changes, but the digital transformation has more rapid exponential ones, especially in the last few decades. The processing power, communication speed, and storage capacity of data have increased massively. Additionally, technological advancement is so blistering that it is hard for people to keep pace with it. This revolution was ever so disruptive in human history, so it is bringing various challenges to the people. Every day, new gadgets, instruments, and machines are integrating into humans' life, so people need to increase their learning agility. Leaders, as significant elements of this world in all senses, are being the primary components needing to adapt and evolve most quickly since they are the role model for the followers. So, their perception and embracement of these challenges matter substantially.

We are living on the brink of a technological revolution that radically changes the ways that we live, we work, and communicate. In its size, ambit, and turmoil, this transformation will be different from everything that humans ever experienced before. The three main reasons that digital transformation is not the only extension of the third industrial revolution but also a distinctive period: the impact of systems, speed, and scope (Schwab, 2016). Businesses that fail to make innovations now will endure a competitive disadvantage eventually - progress in technology means progress in commerce (White, 2019, p. 19). From these challenges, the legacy refers to the far-flung efforts for the integration of new technologies to former infrastructures. Another challenge is resource allocation. Agility - finding agile mindsets, creating an agile team, and finally, scaling agility to the whole organizational structure. Ambidexterity challenge is bringing a balance among the legacy infrastructure, legacy business (from past to now existing systems and existing way of doing business), and innovation. Using start-up companies as a means for creating new ideas, cooperating with them is another point - creating partnerships. The challenge of connectivity is crossing the business's borders for creating a learning environment. Another one is governance. On the other hand, the functional identity is a challenge that requires reconfiguring the collaborative interactions of traditional corporate functions. People are the last challenge, and it refers to creating surroundings for people so that they can build digital skills (Deiser, 2019, pp. 43-56).

\subsection{Technoversal Leader}

The words technology and universal have been inspiring in the creation of the Technoversal. Technology refers to a leader's having a data-driven mindset and increasingly requiring technical skills. Universal, on the other hand, refers to the same leader's sensitively embracing nature along with humans and having a distinct skillset and behaviors - APARTS stands for agility, problem-solving efficiency, adaptation, respect, technology, seeking different perspectives. This leader brings a new behavior set that gets leaders ahead of others, a novel perspective that a business leader should have concerns for other creatures along with humans because the world is on the brink of an environmental collapse and resource scarcity. Technoversal Leader can overcome many challenges that the newworld order causes (Kapucu, 2020). Some of these challenges to overcome are VUCA, and it stands for volatility, uncertainty, complexity, and ambiguity. 
Table 1 - Technoversal Leader Overcoming Challenges by Employing Key Behaviors

\begin{tabular}{|c|c|c|}
\hline Challenge of Digitilized World & $\begin{array}{l}\text { Leader's Responsive } \\
\text { Key Behavior }\end{array}$ & Outcome \\
\hline Volatility, haste, dynamism & Agility & Behavior allows the leader to act quickly. \\
\hline Complexity, variety of factors & $\begin{array}{l}\text { Problem-solving- } \\
\text { efficiency }\end{array}$ & $\begin{array}{l}\text { Skill guides the leader in setting an algorithm for solving } \\
\text { complexity. }\end{array}$ \\
\hline $\begin{array}{l}\text { Uncertainty, an environment difficult to } \\
\text { predict }\end{array}$ & Adaptation & $\begin{array}{l}\text { Behavior prepares the leader to become mentally ready for a } \\
\text { new and uncertain environment. }\end{array}$ \\
\hline $\begin{array}{l}\text { Ethical concerns of digital transformation, } \\
\text { collective leadership, leading a more expert } \\
\text { employee, sensitivity to nature }\end{array}$ & Respect & $\begin{array}{l}\text { By respecting employees, the leader gains their respect and } \\
\text { manage expert employees. Behavior adapts leader to a } \\
\text { collective leadership rather than a hierarchy. And finally, it } \\
\text { helps leaders to have the sensitivity to nature and } \\
\text { environmental sustainability. }\end{array}$ \\
\hline Data-driven mindset, technical knowledge & Technology & Skill allows leaders to have a more data-driven mindset. \\
\hline Ambiguity, absence of clarity & $\begin{array}{l}\text { Seeking different } \\
\text { perspectives }\end{array}$ & $\begin{array}{l}\text { Skill allows the leader to use the power of different minds, } \\
\text { teamwork and having a broader and stronger view against } \\
\text { ambiguity. }\end{array}$ \\
\hline
\end{tabular}

Note. The table emphasizes the key behaviors and skills that can be adopted by individuals who aim to excel in today's and future's leadership and just a part of the challenges that these behaviors can respond to and overcome. Adapted from "Technoversal Leader: Triumphant Leader of the Technological Era." The author has produced and prepared the table, 2020.

Figure 2

Vicious Cycle of a Disruptive Environment

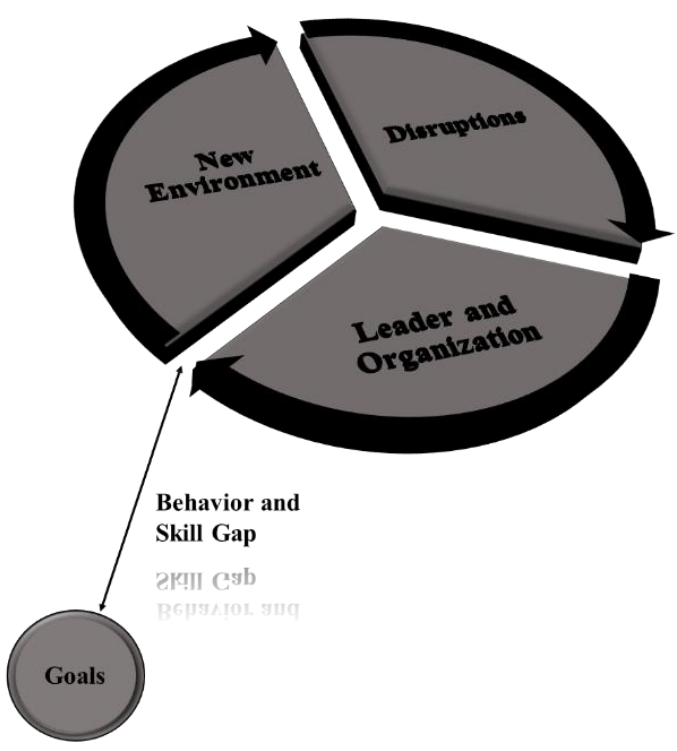

Figure 3

Technoversal Leader Breaking the Vicious Cycle

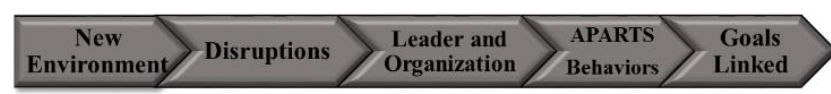

Note. In Figure 2, the chart illustrates the new environment that involves digital transformation. This new environment creates vicious cycles caused by various disruptions, which may generate poor outcomes because behavior and skill gaps can cause externalized organizational goals, making the goals unreachable. In figure 3, the diagram illustrates filling this gap by APARTS behaviors and linking leader and organization to its goals by breaking this unproductive cycle. Adapted from "Technoversal 
Leader: Triumphant Leader of the Technological Era." The author has produced and prepared the figures, 2020.

\section{Findings}

For people, the changes that are surprising at the beginning become ordinary within time. The expectations relevant to technology are so high that the generations born in the 21st century are not easily surprised. Interestingly, the disruption whose dimensions are not easy to perceive became part of daily life. Phenomena and technological advancement conceptually become ordinary. As time passes, leaders get to deal with people who have such a mindset, with high expectations.

In their study, Mihai and Cretu detail the question, the new generation who grew up with intensive use of information technology are changing the corporate culture and leadership models, who are at the center of value creation. And they ask how a leader can handle these changes and utilizes the potential of this new generation $(2019$, p. 65$)$. The answer is that leadership demands different masterfulness and high leverage to lead effectively in the digital era. And these expectations are increasing the number of characteristics defined in literature and business environments.

A recent study that reviewed literature has found 23 characteristics for digital leadership, as a result of calculation by the rate of mention. The difference between the ratios of each behavior mentioned is either close or equal to one another, except innovative visionary and networking intelligence (Klein, 2020, pp. 894-895). The increasing number of leadership styles and the abundance of skills and behaviors assigned to each leadership as necessary to adopt, resulting in an excessive amount of data. That makes it hard to choose the key characteristics that should be adopted by leaders, for a leader, in earlier phases of its career, which may be confusing. And this may be a reason that a sufficient number of leaders cannot raise. And as reported by Korn Ferry, the number of leaders who possess the necessary skill sets and behaviors is not enough (2019), so the majority of leaders think that their organizations need new leaders to be competitive in the digital era (Korn Ferry, 2019; Kane, 2018). And yet, research with a strong focus on employees' and leaders' thoughts, which observes a large population and finds common characteristics in different pieces of research; the research, then, can reduce the number of behaviors to a reasonable point so that they become adoptable and achievable by leaders. And finally, research can show a clear path to potential leaders related to the adoption and choice of these characteristics. This research has a goal to guide to a clear path depending on an objective perspective.

With digital transformation notably, the expectations from leaders highly increased. For the sake of creating effective and efficient leaders and not losing time while raising new-era leaders, the behaviors to focus and improve must be well-defined. One of the required skills is technology since this era also requires leaders who understand it. Even though technology knowledge alone does not appear to be enough for leaders to control, leaders still need to adopt and advance it. Because leaders will have to deal with data-driven-decision making, which is a challenge for leaders (Hesse, 2018); thus, being a data and information mentor is the new role of a leader (Jakubik \& Berazhny, 2017, pp. 471483).

From the beginning of the 2000s or even before, charismatic or visionary business leaders may have defined as great business leaders. Or transactional, transformational, and authentic leadership styles could appear in minds for describing effective and efficient leadership. These traits or styles may also matter today. Yet the spectrum of leadership in the technology world has brought these following behaviors into a must-have position: agility (de Smet et al., 2019, pp. 28-34; Korn Ferry, 2019; Neubauer et al., 2017), adaptation (Deegan et al., 2020; Korn Ferry, 2019; Neubauer et al., 2017), seeking different perspectives (Kane, 2018; Feser et al., 2015), problem-solving efficiency (Feser et al., 
2015; Clarke, 2013, pp. 26-33), and respect (Smith, 2019, pp. 55-58; Porath, 2015) carry primary and vital significance in leadership. These skills and behaviors are central, and they seem to be keeping their indispensability for a long time.

The leader of today and the future is the one who passes beyond traditional and contemporary definitions. This new era leader is the one who brings together former and current qualities of leaders. As a business leader, she or he should give special consideration not only to business but also to all living creatures, considering the dimensions of sustainability: economic, social, and environmental. The new era leader must use technology as a means of serving others and being successful, and she or he must not become vulnerable to become enslaved by technological disruption. Few styles may show a deep sensitivity to concern with all living creatures and the environment. These leaders can be examples: a servant leader (Gandolfi et al., 2017, pp. 351-356), or a transpersonal leader (Grant, 2020, pp. 43-44), or an Altrocentric leader (Jakubik \& Berazhny, 2017, pp. 471-483). Despite the importance of this quality, they may be missing other necessary skills.

It appears the challenges-rooting from the digital transformation and causing an environment that is difficult to control because of the reasons like complexity, volatility-are also creating its solution with the development of technology. Technology ignites challenges, and then technology responds to this challenge that is created by itself, and then it creates another new challenge. In some cases, it turns into a self-created-problem-solution cycle. On the other hand, some challenges to overcome digital disruption overlap with the skills and behaviors that the leaders of the digital era should possess. I.e., the leader's relevant ability or behavior becomes responsive in creating solutions to the problems. Building an agile team and reaching such an organizational structure, agility is a challenge for digital transformation (Deiser, 2019, pp. 43-56) and a must-have behavior for leaders' success (de Smet et al., 2019, pp. 28-34).

Volatility, uncertainty, complexity, and ambiguity (VUCA) define the environmental conditions of recent years (Kraaijenbrink, 2018).

VUCA factor is just one of the symbols referring to the current challenges, and each of which can be related to confrontations in becoming a leader in the digital era. And many business leaders have to be prepared against them. So, a leader who possesses the agility behavior can respond to the haste and dynamism, which would let the leader take necessary actions in the volatility. Uncertainty denoting an environment that is difficult to predict and to project can be solved by adaptation, which can make a leader ready for many conflicts that may arise. Seeking different perspectives and problemsolving efficiency can answer the complexity referring to an ample quantity of factors to consider and the ambiguity meaning the absence of clarity. These qualities may well solve more problems and overcome the challenges of today and the future, like VUCA or different than them.

Gamification may be a tool for raising leaders, yet the fast-paced environment obliges leaders to adapt to new behaviors. Thus, the games require up-to-date content and design that match the needs of today's leadership. As a long-term strategy, these factors can be keys for companies that are investing in gamification and for leaders' successes who become part of these programs.

The Management and Leadership Summit mediated to find common behaviors of successful leaders, and it has brought out implications about leaders' views for digital transformation.

A Chief Information Officer pointed out the relation between digitalization and the human factor. "Digitalization is not only to exploit technology but also it is change management of human factor." And "The human mind is resistant to exponential change, and it is open to linear change. Corporations are trying to get used to digital [exponential] change." (Leader GE). 
A sourcing director has emphasized the importance of this change and digital transformation. "Corporations that cannot keep pace with technology and digitalization will disappear between three to five years." (Leader SK).

A CEO, on the other hand, thinks that investment in technology would return. And he lays stress on that, "If leader invests in technology, economy pays back." (Leader CD).

And the findings from the interviews, the last stage, interviewing leaders, has led to some specific details, and each question (Appendix $\mathrm{C}$ ) has also given a general understanding. Overall results and details of the answers are subsequently listed below.

The interviewees' thoughts regarding the key behaviors that a leader should possess shows similarities with the other stages of the research. They think that the leader in the digital era and the future should possess agility, problem-solving efficiency, and technology skills. Additionally, being innovative has been another point indicated by leaders. A CEO says:

After the 2000s, especially in the last decade, digitalization was very rapid. Regarding the employee competencies, along with university education and language, social media use is very important. New age leaders will be the ones who understand and exploit digital transformation. (Leader GA).

Against the question about difficulties handling new technologies, their common problem interestingly shows up not as the technology itself but organizational culture, the cultural resistance that individuals demonstrate. Adaptation is another problem to point. A company owner provides a different point of view than other leaders for this question:

Productivity increased with industry 4.0, and the necessity for labor decreased.

Thus, places like Europe that have high labor costs are becoming competitive owing to industry 4.0. For some products, the price difference is decreasing. The companies which do not invest in technology cannot easily sustain. (Leader EA).

About the leadership style best fits in today's rapidly-changing environment, except for a few leaders, no leader gave leadership styles defined in the literature. They majorly provided behaviors and skills instead. Few still think autocratic leadership can be valid. Yet, the majority think leaders must be adaptive, democratic, transformational, and a leader who looks for different opinions. A company owner says, "Our friends' [employees] educational backgrounds and behavioral patterns advanced much, so we need to be sharing. We must respect people's decisions, and we must value their perspectives. The new generation has good decision-making skills." (Leader OCÇ).

A key question in understanding digital transformation and leader interaction, if digital transformation affects the leader behaviors. Leaders have given a direct answer to this question. Over 92 percent of leaders think that digital transformation has effects on leader behaviors. A company owner explains this interaction:

Indeed, it has effects. Owing to digital transformation, distance education and remote management concepts have become part of our life. Remotely leading is a part of our lives. There will be differences between online and face-to-face leadership. The new generation will be more successful in leading people remotely, and this is not something that the old one can handle. (Leader OcÇ).

Another primary question in understanding digital transformation, leader, and follower interaction, if digitalization brought changes in follower expectations. Over 92 percent of leaders think 
that follower expectations changed with digital transformation. An Engineering Department Manager observed:

Along with digitalization, especially the productivity of the operators in control of machines, who work as per targets, can easily be measured, and a fair wage policy can execute. A leader's followers expect the leader to use the digitals operated for measuring the performance. (Leader SY).

\section{Discussions}

Although their names are a direct link to digitalization, industry 4.0 leadership or digital leadership should not only limit and conceptualize to a digital environment. I.e., digital leadership should refer to a skill that needed to be adopted by different leadership styles that want to sustain in the digital era (to technology and human interaction skill that enables adapting to digital challenges).

Technology ignites challenges, and then technology responds to this challenge that is created by itself, and then it creates another new challenge. In some cases, it turns into a self-created-problemsolution cycle. For example, an excessive amount of stored data makes it hard for the human mind to perceive this exponentially-grown complex structure of data on one side. The exponential processing power and communication speed of data (technology itself) bring the solution to analyze and interpret this mass of data. In environmental issues, it is similar to this. Technology as a solution mechanism to many problems may trigger simultaneous informational and environmental matters because human errors and feelings are coming into play as a variable. Businesses may use technological machinery that pollutes the environment, and other technologically advanced products clear this pollution.

Business leaders should focus on the environmental sustainability dimension. Their responsibilities against nature should more often become subject to the studies of this business dimension. They must have concerns for animals, plants, and they must universally embrace all creatures for a habitable better world.

The misuse of technology, even a temporary loss of control over it, may cause dire consequences. If the purpose of artificial intelligence is replicating human emotions and behaviors, which behaviors it will copy, who the ideal human is, and will the algorithms solve the frailties of human nature? It is another point that must be taken further by scholars.

The number of effective and efficient leaders is not enough, so businesses need to develop leaders. One of the reasons for not having a sufficient number of leaders can be lacking the determination of the vital behaviors, thus, not focusing on skills that are primary concerns of this era, and as a cause-effect failing to develop the ideal leaders. In light of objectivity, careful research can determine the critical points and reduce the primary characteristics to a distinct set that distinguishes a great leader from others. APARTS behaviors are crucial for new-era leaders. Interestingly, the number of leadership styles remains vast. This large number of leadership styles indicate the eagerness to research for finding the ideal leader. Despite there is still ambiguity at this point, the Technoversal leader can well answer the needs of leadership (Kapucu, 2020). On the other side, institutions and researchers must collaborate more for the sake of showing a clear path to potential leaders and raising new-era leaders.

\section{Conclusions}

Change of mindset, design of the business architecture, and communicating effectively with all stakeholders. Cultural change is one of the primary issues for leaders to handle not only in the digitalization of business but also as a more general challenge that leaders need to be prepared against and adopted in the digital era. 
A primary challenge in organizations is culture and skills. The perspective and attitudes of an entire organization signify more than IT infrastructure (Oberer \& Erkollar, 2018; Rogers, 2016).

A characteristic for leaders and organizations to adopt in the market economy is to learn. And agile learning as a prior behavior to catch up with this intensive environment, in a creative economy where added value depends on innovation and learning agility.

There are many different opinions related to the best leadership. Yet, agility, problem-solving efficiency, adaptation, respect, technology, and seeking different perspectives are primary skills and behaviors for controlling businesses and overcoming challenges in the digital era. The digital age procreates difficulties such as change of mindset and culture, which urges leaders to change their behavior to become more adaptive. One of the other challenges that the digital era causes, which is the exponential growth of data processing, communication, and storage. It is one of the reasons why leaders need to have a data-driven mindset and adapt to technology. On the other hand, this acceleration requires leaders to be more agile to keep up with the digital era and align their behavior to agility to become effective and efficient today and in the future.

For applying these key behaviors to leadership, some methods may act as catalysts. "Behavioral protocol," (Grigsby, 2015, pp. 125-128) or gamification (Avolio et al., 2014, pp. 105-126).

Finding talented people and increasing their skills for being a leader is difficult in these times. Because leaders not only need to adapt their style and organization to the surroundings but also obtain these capabilities that they have not got the need for them before (Kane, 2018).

Along with the employment of more experts at businesses that digitally transform not to fall behind others, these professionals might have more knowledge and expertise than the people who lead them. Under these circumstances, traditional hierarchical styles will need to adapt their unilateral behaviors into more participative and positive ones. Digital transformation may challenge and affect such characteristics of managers used to steer in such a hierarchical structure, yet they will have to seek different perspectives to survive.

At various dimensions of this significant subject-technology, digital transformation, and leader interaction - gaps exist (Bolden \& O'Regan, 2016, pp. 438-439; Khan, 2016; Avolio et al., 2014, pp. 105-126). These last few years have not significantly changed the research progress on this particular subject. It represents an opportunity for researchers to take such types of research further.

Not hierarchical, but collective leadership is more convenient today. Being an omnipotent ruler is no longer useful and trying to be an omniscient leader is also obsolete. Leaders must be ready to collaborate with others who are better than them. And performance is an outcome of behavior (Rodríguez et al., 2019, pp. 22-24).

Ubiquity and remotely leading people matter in the global environment.

The communications remotely take place via various means of technology in the virtual environment. Traditional communications that are occurring in the physical world are becoming less routine and less effective in the globalizing world (McCann \& Kohntopp, 2019, pp. 26-29).

Digital transformation brings on challenges for business leaders. Leaders have to deal with data-driven decision making, disruptive changes in the landscape of commercial activities, work 
organized via digital services, the workforce with ubiquitous access to information, and this power adding new methods of communication (Hesse, 2018).

Ethical issues may arise for leaders because of digital transformation.

Information overload on employees may make the lines indistinct that separate personal and work life. On the other side, digitalization offers new possibilities like virtual teams, introduces new means of communication, increases speed and access to information, impacts power structures, thus, causes efficiency, standardization, and smart working (Cortellazzo et al., 2019, pp. 1-13).

Creating skilled and engaged teams appears as a requirement for leaders in the digital age (Bawany, 2019, p. 28; Della Corte et al., 2019), and the organizations and leaders must realize that the most substantial challenge of digital transformation comes from necessary talent absence (Sainger, 2018, pp. 2-5).

Evidently, along with opportunities, digital transformation brings issues and challenges. Technology and digital transformation will continue to represent a large field in economics, and it will progress by bringing many novelties along with challenges. It will increasingly keep leaders' agenda busy for a very long time, and maybe irrevocably. So, businesses and leaders should become immune to digital transformation and technology.

\section{Funding}

There are not any individuals or legal entities (commercial, not-for-profit, or public) that has provided any funding during the completion of this research.

\section{Acknowledgment}

This article originates from a thesis that is also prepared by the author Hakan Kapucu.

\section{References}

Avolio, B. J., Sosik, J. J., Kahai, S. S., \& Baker, B., 2014. E-leadership: Re-examining transformations in leadership source and transmission. The Leadership Quarterly, 25(1), pp. 105-106, 121, 126. https://doi.org/10.1016/j.leaqua.2013.11.003

Bawany, S. (2019, February). Leadership 4.0: How ready are you to be a digital leader? Leadership Excellence, 36(2), p. 28.

Bolden, R. \& O'Regan, N., 2016. Digital disruption and the future of leadership: An interview with Rick Haythornthwaite, Chairman of Centrica and Mastercard. Journal of Management Inquiry, 25(4), pp. 438-439. doi: $10.1177 / 1056492616638173$.

Chappelow, J., 2020. Kondratiev wave. Retrieved June 03, 2020, from https://www.investopedia.com/terms/k/kondratiev.asp

Clarke, S., 2013. Safety leadership: A meta-analytic review of transformational and transactional leadership styles as antecedents of safety behaviors. Journal of Occupational and Organizational Psychology, 86(1), pp. $26,33$.

Cortellazzo, L., Bruni, E., \& Zampieri, R., 2019. The role of leadership in a digitalized world: A review. Frontiers in Psychology, August 2019, 10, pp. 1-2, 11-13. doi: 10.3389/fpsyg.2019.01938.

Deegan, C., Seyhanlı, S., Kaynak, Ö., Açık, C., Bilgiç, G., Kurt, S., Kaynar, Ş., Kayan, D., Alp, H., Çebi, A. N., Erol, G., Türkölmez, T., \& Oktay, A. (2020, March). Management and Leadership Summit. Symposium conducted at the meeting of Boğaziçi University Management and Economics Club, Istanbul, Turkey. 
Deiser, R. (2019, April). 9 digital transformation challenges. Developing Leaders. (32), pp. 43-56.

Della Corte, V., del Gaudio, G., \& Sepe, F., 2019. Leadership in the digital realm: What are the main challenges? doi: 10.5772/intechopen.89856. Retrieved from

https://www.intechopen.com/books/digital-leadership-a-new-leadership-style-for-the- 21stcentury/leadership-in-the-digital-realm-what-are-the-main-challenges-

de Smet, A., Lurie, M., \& St. George, A., 2019. Leading agile transformation the new capabilities leaders need to build 21st-century organisations. The Building Economist, June 2019, parts 3-5, pp. 28, 34.

Feser, C., Mayol, F., \& Srinivasan, R. (2015, January). Decoding leadership: What really matters. McKinsey Quarterly. Retrieved from

https://www.mckinsey.com/featured-insights/leadership/decoding-leadership-what-really-matters\#

Gandolfi, F., Stone, S., \& Deno, F., 2017. Servant leadership: An ancient style with $21^{\text {st }}$ century relevance. Review of International Comparative Management, 18(4), pp. 351-352, 356.

Giroux, T. \& Mclarney C., 2014. Exploring the leadership continuum: The relevance of transformational leadership on organizational performance. Proceedings for the Northeast Region Decision Sciences Institute, p. 863.

Grant, D. (2020, March). Excellent leadership is transpersonal. Leadership Excellence, 37(3), pp. 43-44.

Grigsby, R. K., 2015. Enhancing the behavioral science knowledge and skills of 21st-century leaders in academic medicine and science. Journal of Organizational Behavior Management, 35(1-2), pp. 125-126, 128. doi: 10.1080/01608061.2015.1031428.

Hesse, A., 2018. Digitalization and leadership - how experienced leaders interpret daily realities in a digital world. Proceedings of the 51st Hawaii International Conference on System Sciences. Retrieved from https://scholarspace.manoa.hawaii.edu/handle/10125/50121

Jakubik, M. \& Berazhny, I., 2017. Rethinking leadership and its pratices in the digital era. Management International Conference, pp. 471-483.

Kane, G. C. (2018, July). Common traits of the best digital leaders. MIT Sloan Management Review. Retrieved from https://sloanreview.mit.edu/article/common-traits-of-the-best- digital-leaders/

Kapucu, H., 2020. Technoversal leader: Triumphant leader of the technological era. International Journal of Progressive Sciences and Technologies, 23(1), pp. 440-446. Retrieved from http://ijpsat.es/index.php/ijpsat/article/download/2313/1330

Khan, S., 2016. Leadership in the digital age - a study on the effects of digitalisation on top management leadership (Master's thesis). Available from Digitala Vetenskapliga Arkivet at Stockholm University. Retrieved from https://su.diva-portal.org/smash/get/diva2:971518/FULLTEXT02.pdf

Klein, M., 2020. Leadership characteristics in the era of digital transformation. Business \& Management Studies: An International Journal, 8(1), pp. 894-895. doi: 10.15295/BMIJ.V8I1.1441.

Korn Ferry, 2019. The self-disruptive leader. Retrieved from https://focus.kornferry.com/wp-content/uploads/2015/02/KF-Disruptive-Leader-Final-DigitalSpreads FINAL.pdf

Kraaijenbrink, J., 2018. What does VUCA really mean? Retrieved March 23, 2020, from https://www.forbes.com/sites/jeroenkraaijenbrink/2018/12/19/what-does-vuca-really-mean

Larjovuori, R. L., Bordi, L., \& Tammi, K. H., 2018. Leadership in the digital business transformation. Proceedings of the 22nd International Academic Mindtrek Conference, pp. 1, 6-7. https://dl.acm.org/doi/pdf/10.1145/3275116.3275122

Marvasti, A. B., 2019. Qualitative content analysis: A novice's perspective. Forum: Qualitative Social Research, 20(3).

Mayring, P., 2014. Qualitative content analysis: Theoretical foundation, basic procedures and software solution, pp. 10-15, 95. 
McCann, J. \& Kohntopp, T., 2019. Virtual leaders in organizations: Potential competitive advantage? Advanced Management Journal, 84(3), pp. 26-27, 29.

Mihai, R. L. \& Cretu, A., 2019. Leadership in the digital era. Valahian Journal of Economic Studies, 10(24)(1), p. 65. doi: 10.2478/vjes-2019-0006.

Neubauer, R., Tarling, A., \& Wade, M., 2017. Redefining leadership for a digital age. Global Center for Digital Business Transformation and metaBeratung $\mathrm{GmbH}$. Retrieved from https://www.imd.org/globalassets/dbt/docs/redefining-leadership

Oberer, B. \& Erkollar, A., 2018. Leadership 4.0: Digital leaders in the age of industry 4.0. International Journal of Organizational Leadership, 7(4), doi: 10.33844/ijol.2018.60332.

Porath, C. (2015, May). The leadership behavior that's most important to employees. Harvard Business Review. Retrieved from https://hbr.org/2015/05/the-leadership-behavior-thats-most-important-to-employees

Prince, K. A., 2017. Industrie 4.0 and leadership. Proceedings of The 17th International Conference on Electronic Business, pp. 132-139.

Rios, M. A. R., Lopez, J. B. L., \& Veiga, J. G., 2018. The fifth global Kondratiev. Low economic performance, instability and monopolization in the digital age. Marketing and Management of Innovations, (2), p. 270. doi: 10.21272/mmi.2018.2-22.

Robbins, S. P. \& Coulter, M. A., 2016. Being an effective leader. Management (13th ed.), pp. 524-535. Malaysia: Pearson.

Rodríguez, M., Rodríguez, C., Robson, T., \& Newman, L., 2019. Leaders who inspire: Today, their best asset is soft skills: communication, openness, and a focus on client and employee experience. Latin Trade, Q 3, pp. 22-24.

Rogers, D. L., 2016. The digital transformation playbook: Rethink your business for the digital age. New York: Colombia University Press.

Sainger, G., 2018. Leadership in digital age: A study on the role of leader in this era of digital transformation. International Journal on Leadership, 6(1), pp. 2, 5.

Schreier, M., 2012. What is qualitative content analysis? Qualitative content analysis in practice, p. 1. London: Sage.

Schwab, K., 2016. The fourth industrial revolution: What it means, how to respond. Retrieved from https://www.weforum.org/agenda/2016/01/the-fourth-industrial-revolution-what-it-means-and-how-torespond/

Smith, D. F. (2019, August). Five key leader behaviors that keep your best staff on your team. Podiatry Management, pp. 55-56, 58.

The Economist Intelligence Unit, 2017. Building leaders without silos. Retrieved from https://eiuperspectives.economist.com/strategy-leadership/building-leaders-without-silos/whitepaper/building-leaders-without-silos

University of Virginia \& Boston Consulting Group, 2018. In Digital Transformation. Retrieved April 17, 2020, from https://www.coursera.org/learn/bcg-uva-darden-digital-transformation

White, P., 2019. What does digital transformatilon really mean in a workplace? Database and Network Journal, 49(4), p. 19. 


\section{An Analysis of Leaders for Finding Their Common Behaviors}

\begin{tabular}{|c|c|c|c|c|c|c|c|c|c|c|c|c|c|c|c|}
\hline & & \multirow[b]{2}{*}{$\begin{array}{l}\text { Set of Behaviors } \\
\text { and Qualities }\end{array}$} & \multirow[b]{2}{*}{$\begin{array}{l}\text { Being } \\
\text { Altruist }\end{array}$} & \multirow[b]{2}{*}{$\begin{array}{l}\text { Being } \\
\text { Amenable }\end{array}$} & \multicolumn{8}{|c|}{ According to the Leaders, the Set of Behaviors and Qualities That Any Leader Should Have } & \multirow[b]{2}{*}{$\begin{array}{l}\text { Being } \\
\text { Innovative }\end{array}$} & \multirow[b]{2}{*}{ Creativity } & \multirow[b]{2}{*}{$\begin{array}{l}\text { y Emotional } \\
\text { Intelligence }\end{array}$} \\
\hline & & & & & Resilience & $\begin{array}{l}\text { Learning } \\
\text { Agility }\end{array}$ & $\begin{array}{l}\text { Adapt to } \\
\text { Digital } \\
\text { Era }\end{array}$ & $\begin{array}{l}\text { Being } \\
\text { Visionary }\end{array}$ & Teamwork & Adaptation & $\begin{array}{l}\text { Being } \\
\text { Distinctive } \\
\text { as a } \\
\text { Person }\end{array}$ & Agility & & & \\
\hline Company & Title & Name Surname & & & & & & & & & & & & & \\
\hline Vodafone Turkey & CEO & $\mathrm{CD}$ & & 1 & & & 1 & & & 1 & & & & & \\
\hline Nestle Turkey & Business Executive Officer & $\mathrm{rSS}$ & & 1 & & & & & 1 & 1 & & & & & \\
\hline GlaxoSmithKline Turkey & CEO & ÖK & & & 1 & & & & & & 1 & & & & \\
\hline Pfizer Turkey & CEO & $\mathrm{CA}$ & 1 & & & & & 1 & & & & & & & \\
\hline British American Tobacco & CEO & GB & & 1 & & & & & & & 1 & & & & \\
\hline Unilever Turkey & Sourcing Unit Director & SK & & & & 1 & 1 & & & & & 1 & 1 & 1 & 1 \\
\hline Korn Ferry Turkey & Honorary Chairman & ŞK & 1 & 1 & 1 & 1 & & & & & & & & & \\
\hline Phillip Morris International & Group Manager & DK & & & 1 & & & & & & 1 & & & & \\
\hline Yapı Kredi Turkey & Vice General Director & HA & & & & & 1 & 1 & & & & & & & \\
\hline Beşiktaş JK & President & ANÇ & & 1 & 1 & & & & 1 & 1 & & & & & \\
\hline Yildı Holding Turkey & $\mathrm{CIO}$ & GE & & & & 1 & 1 & & & & & & & & \\
\hline Hayat Emeklilik and Bank & $\mathrm{CEO}$ & TT & & & & 1 & & & & & 1 & & & & \\
\hline \multirow[t]{2}{*}{ Anadolu Grubu Turkey. } & Talent Management Execu & $\mathrm{AO}$ & & & 1 & 1 & & & & 1 & & & & & \\
\hline & & Aggregate & 2 & 5 & 5 & 5 & 4 & 2 & 2 & 4 & 4 & 1 & 1 & 1 & 1 \\
\hline
\end{tabular}


Appendix B

Basic Statistics of Interviews

\begin{tabular}{|c|c|c|c|c|c|c|c|c|c|c|}
\hline $\begin{array}{l}\text { Number of } \\
\text { Companies }\end{array}$ & $\begin{array}{l}\text { Name of } \\
\text { Company }\end{array}$ & Title & $\begin{array}{c}\text { Name and } \\
\text { Surname }\end{array}$ & Age & Education & $\begin{array}{c}\text { Experience } \\
\text { in Years }\end{array}$ & Phone & Email & $\begin{array}{c}\text { Duration in } \\
\text { Minutes }\end{array}$ & $\begin{array}{c}\text { Number of } \\
\text { Interviewees }\end{array}$ \\
\hline 1 & & $\begin{array}{c}\text { CEO } \\
\text { Engineering } \\
\text { Department } \\
\text { Manager }\end{array}$ & & 62 & Undergraduate & 40 & & & 52 & 1 \\
\hline & & $\begin{array}{c}\text { Purchaising } \\
\text { Manager }\end{array}$ & & 35 & Undergraduate & 7 & & & 60 & 3 \\
\hline & & $\begin{array}{c}\text { Regional } \\
\text { Responsible }\end{array}$ & & 40 & Undergraduate & 15 & & & 30 & 4 \\
\hline 2 & & Owner & & 47 & Undergraduate & 27 & & & 32 & 5 \\
\hline 3 & & $\begin{array}{c}\text { Sales \& } \\
\text { Marketing } \\
\text { Coordinator }\end{array}$ & & 38 & Undergraduate & 12 & & & 30 & 6 \\
\hline & & $\begin{array}{c}\text { R \& D } \\
\text { Manager }\end{array}$ & & 40 & Graduate & 10 & & & 30 & 7 \\
\hline 4 & & $\begin{array}{c}\text { Sales } \\
\text { Manager }\end{array}$ & & 42 & Undergraduate & 19 & & & 30 & 8 \\
\hline 5 & & Sales Director & & 46 & High School & 16 & & & 31 & 9 \\
\hline 6 & & Owner & & 32 & Graduate & 10 & & & 30 & 10 \\
\hline 7 & & $\begin{array}{c}\text { Store } \\
\text { Manager }\end{array}$ & & 46 & 2 Years University & 26 & & & 30 & 11 \\
\hline 8 & & $\begin{array}{l}\text { Mechanical } \\
\text { Engineer \& IT } \\
\text { Responsible }\end{array}$ & & 41 & Undergraduate & 16 & & & 45 & 12 \\
\hline 9 & & $\begin{array}{l}\text { Marketing } \\
\text { Manager }\end{array}$ & & 31 & Undergraduate & 11 & & & 45 & 13 \\
\hline $\begin{array}{c}\text { Total } \\
\text { Companies }\end{array}$ & & & & $\begin{array}{c}\text { Avarage } \\
\text { Age } \\
\text { Years }\end{array}$ & & \begin{tabular}{|c|} 
Avarage \\
Experience \\
Years \\
\end{tabular} & & & $\begin{array}{l}\text { Avarage } \\
\text { Minutes }\end{array}$ & $\begin{array}{c}\text { Total } \\
\text { Interviewees }\end{array}$ \\
\hline 9 & & & & 41,4 & & 17 & & & 39 & 13 \\
\hline
\end{tabular}


Appendix C

Interview Questions

\begin{tabular}{|l|l|l|l|}
\hline Position: & Age: & $\begin{array}{l}\text { Education } \\
\text { Level: }\end{array}$ & $\begin{array}{l}\text { Experience- } \\
\text { Year: }\end{array}$ \\
\hline \hline Gender: & $\begin{array}{l}\text { Does Your } \\
\text { Company Operate } \\
\text { in Intermediate } \\
\text { Goods Industry? } \\
\text { Yes or No: }\end{array}$ \\
\hline \hline $\begin{array}{l}\text { Shortly, Can You Describe Your Social Media and Social Software Use } \\
\text { and Experience in the Company? }\end{array}$ & \\
\hline
\end{tabular}

1 What are the key behaviors that a leader should possess in the digital era and the future?

2 Do you have any experience that you had difficulty handling in new technologies? Can you give an example, something critical that affected your way of doing business?

3 While you consider the conditions that rapidly change in businesses and the environment, which leadership style would best fit in today's rapidly-changing environment?

4 What do you think about digitalization and digital transformation?

\section{Do you think that digital transformation has effects on leader behaviors? If you think} that it has, could you tell these effects by giving examples?

6 What does digitalization mean for your industry and company?

7 Has digitalization brought about changes in follower expectations?

8 What does digitalization mean for you in your role as a leader?

9 What does digitalization mean for your communication behavior in private life and your job?

10 Do you recognize any further changes in further areas concerning digitalization in your business?

11 How do you think digitalization will influence leadership in the future? 